\title{
Persistence of sputum eosinophilia in children with controlled asthma when compared with healthy children
}

\author{
Y. Cai*, K. Carty*, R.L. Henry**, P.G. Gibson*
}

Persistence of sputum eosinophilia in children with controlled asthma when compared with healthy children. Y. Cai, K. Carty, R.L. Henry, P.G. Gibson. (OERS Journals Ltd 1998.

ABSTRACT: We aimed to describe induced sputum cell counts in healthy nonasthmatic children, and to compare these to children with controlled and uncontrolled asthma.

Following clinical assessment and spirometry, ultrasonically nebulized hypertonic saline was used to induce sputum from children with asthma $(n=50)$ and without asthma $(n=72)$. Sputum was dispersed and cell counts performed to yield total and differential cell counts. Specific stains were used for eosinophil and mast cell counts. All of the children with asthma were receiving inhaled and/or oral corticosteroids. Current asthma control was assessed in terms of symptoms and lung function. Children were classified as controlled on inhaled corticosteroids (no current symptoms, normal lung function $n=15)$, current symptomatic asthma $(n=16)$ and asthma exacerbation $(n=11)$.

It was found that eosinophils comprised a median $0.3 \%$ (interquartile range (IQR): $0,1.05)$ of cells in sputum from healthy children. Sputum eosinophils $(4.3 \%$ (IQR: $1.5,14.1) \mathrm{p}=0.0005)$ and epithelial cells $(14 \%$ (IQR: $6,19.4) \mathrm{p}=0.0005)$ were significantly higher in children with asthma than in nonasthmatic children. Children whose asthma was controlled, as well as those with symptoms, had more sputum eosinophils and epithelial cells than the nonasthmatics. Mast cells were found in the sputum of only four of the $\mathbf{4 2}$ children with asthma.

This study demonstrates that eosinophilic airway inflammation and epithelial damage can occur in children with asthma. Airway inflammation persists even in those children who are receiving inhaled corticosteroids, have normal lung function and good symptomatic control of their disease.

Eur Respir J 1998; 11: 848-853.
*Airway Research Centre, Respiratory Medicine Unit, John Hunter Hospital, Australia. **The Discipline of Paediatrics, University of Newcastle, New South Wales, Australia.

Correspondence: P.G. Gibson

Airway Research Centre

Respiratory Medicine

John Hunter Hospital

Locked Bag 1

Hunter Region Mail Centre

NSW 2310

Australia

Fax: 61249213469

Keywords: Asthma

childhood

eosinophil

normal values

sputum

Received: May 141997

Accepted after revision November 291997
Airway inflammation is regarded as a central feature of asthma in both children and adults [1]. The typical features include an infiltrate of eosinophils, mast cells and T-lymphocytes, together with structural changes to the airway wall. Suppression of airway inflammation and control of asthma by inhaled prophylactic therapy remains an important goal of asthma therapy. At present, there are few studies on airway inflammation in childhood asthma, and it is not clear whether airway inflammation is suppressed when asthma is controlled. This is important information which has bearing on both the intensity and duration of inhaled prophylactic therapy in childhood asthma.

Recent studies have shown that corticosteroids have a potent effect on asthmatic airway inflammation, raising the possibility that inflammation is suppressed in controlled asthma $[2,3]$. However, the observation of persistent inflammation in adults with "mild" asthma taking $\beta$-agonists only [4] suggests that airway inflammation could be present even in controlled asthma. These studies may not be readily applicable to children since the classification of asthma severity in adults is different to childhood asthma. For example, subjects classified as "mild" in many adult studies have persistent symptoms requiring daily $\beta$-ago- nist therapy. In children, this would be classified as persistent asthma, consistent with moderate to severe disease.

Addressing the role of airway inflammation in controlled asthma requires direct measurement of the presence and severity of airway inflammation. Induced sputum is a noninvasive method of assessing airway inflammation which is suitable for use in children [5]. The interpretation of whether airway inflammation is present in children with controlled asthma depends on a knowledge of normal values for markers of inflammation in sputum. Therefore, the first aim of this study was to describe total and differential cell counts in sputum induced by hypertonic saline in healthy nonasthmatic children. The second aim was to compare induced sputum cell counts in children with controlled and uncontrolled asthma to those from children without asthma. We hypothesized that: 1) sputum total cell counts, eosinophils and mast cells would be higher in asthmatic than nonasthmatic children; 2) sputum total cell counts, eosinophils, neutrophils and mast cells would be higher in children whose asthma was unstable compared to those whose asthma was stable; and 3) sputum total and differential cell counts would be similar in normal children and those with excellent control of their asthma. 


\section{Methods}

\section{Assessment of normal controls}

Healthy nonasthmatic children were identified from an epidemiological study. A cohort of 263 healthy full-term infants were recruited for a longitudinal study of the development of mucosal immunity and the occurrence of allergy and respiratory disease, especially asthma $[6,7]$. The clinical features of these children have been followed since birth and they were re-evaluated between the ages 8-14 yrs. A total of 170 children attended the John Hunter Hospital as part of a follow-up survey which involved: 1) completing a questionnaire containing validated items including the presence of respiratory symptoms, asthma as diagnosed by a doctor, asthma therapy and a family background of respiratory and allergic diseases [7]; 2) allergy skin-prick testing; 3) spirometry; 4) hypertonic saline challenge; 5) sputum induction; and 6) nasal smears. The 72 children from this study who fulfilled each of the following criteria were regarded as normal controls:

1) Never wheezed; based upon negative response to the question: "has your child ever wheezed? (Wheeze is a whistling noise which comes from the chest)".

2) Never diagnosed as having asthma; based upon a negative response to the question "has your child ever been diagnosed as having asthma by a doctor or hospital?".

3) A fall in forced expiratory volume in one second (FEV1) of $<15 \%$ of predicted value after hypertonic saline challenge [8].

4) Baseline FEV1 ̌̌ $80 \%$ pred [9].

A child was considered atopic if a weal diameter $3 \mathrm{~mm}$ or greater developed 15 minutes after skin prick testing for any of the allergens (house-dust mite, mould mix, mix-ed grass, cat fur and cockroach.

Hypertonic saline challenge. Antihistamines were withheld for $48 \mathrm{~h}$ prior to testing. After spirometry, children proceeded to the hypertonic saline challenge [8] and sputum induction. Saline $(4.5 \%)$ was inhaled for doubling time periods (30 s, 1, 2, $4 \mathrm{~min}$ ) from a Timeter MP500 ultrasonic nebulizer (Oregon, Pike, Pa, USA) with $23 \mathrm{~cm}$ corrugated tubing and a Hans Rudolph 2700 two-way nonrebreathing valve box (Hans Rudolph Inc, Kansas City, Kansas, USA) with rubber mouthpiece and noseclips. FEV1 was measured, in duplicate, $60 \mathrm{~s}$ after each saline dose after which the children were asked to expectorate into a sterile container. The test was stopped when the FEV1 had fallen by $>20 \%$ or 15.5 cumulative minutes nebulization time had elapsed. If the FEV1 fell by $>20 \%$ during the challenge, then salbutamol $200 \mu \mathrm{g}$ was administered using a pressurized metered dose inhaler and valved holding chamber. The dose of $4.5 \%$ saline delivered to the mouth was assessed by weighing the nebulizer cup, tubing and valve-box before and after each challenge. Sputum was collected and processed as described below.

Nasal cytology. Nasal cytology was performed using saline moistened, cotton tipped swabs inserted into the nares beneath the inferior turbinate. The swab was placed against the nasal mucosa and withdrawn in a spiral fashion. It was then spread thinly over glass slides prior to fixation and staining. Smears were stained with May-Grunwald-
Giemsa (MGG) for examination of the eosinophils (one slide) and with toluidine blue after Carroy's fixation for metachromatic cells $[10,11]$.

\section{Assessment of children with asthma}

Subjects. A total of 50 children 6-18 yrs of age who were attending the Paediatric Respiratory Clinic for regular follow-up visits or who were attending the Children's Respiratory Laboratory for lung function tests were recruited into this study. The children performed spirometry before and after $\beta$-agonist administration, followed by sputum induction. Sputum induction was unsuccessful in eight (16\%) subjects who were excluded from further analysis. A questionnaire was administered by either a doctor or a nurse and sought details of asthma symptoms and treatment over the previous 2 weeks, as detailed in table 1 .

Based upon the results of these questions, children were classified into three groups: asthma controlled on inhaled corticosteroids, symptomatic uncontrolled asthma, and current exacerbation of uncontrolled asthma. Asthma controlled on ICS referred to children who had none of the symptoms described in table 1 , whose peak expiratory flow (PEF) was at its best, who were not requiring $\beta_{2}$-agonist therapy for acute symptom relief and whose baseline FEV1 was Š $80 \%$ pred. A child with one or more positive

Table 1. - Characteristics of children with asthma controlled on inhaled corticosteroids (controlled) and uncontrolled asthma (symptomatic and exacerbation)

\begin{tabular}{lcc}
\hline & $\begin{array}{c}\text { Controlled } \\
(\mathrm{n}=15)\end{array}$ & $\begin{array}{c}\text { Uncontrolled } \\
(\mathrm{n}=27)\end{array}$ \\
\hline Lung function & $107.5 \pm 3.8$ & $89.2 \pm 3.1^{+}$ \\
FEV $1 \%$ pred & $0(0)$ & $6(22 \%)$ \\
Baseline FEV1 <80\% pred & $100.5 \pm 6.3$ & $74.2 \pm 5.7+$ \\
FEF25-75\% \% pred & $8.14 \pm 2.6$ & $11.3 \pm 2.7$ \\
BDR \% baseline FEV 1 & & \\
Treatment, past 2 weeks & $15(100)$ & $26(96)$ \\
IC n $(\%)$ & $947 \pm 95$ & $848 \pm 84$ \\
$\quad$ dose $\mu \mathrm{g}$ & $0(0)$ & $9(33)$ \\
OC & $15(100)$ & $25(93)$ \\
$\beta_{2} \quad \mathrm{n}(\%)$ & 1.6 & 2.6 \\
times daily & $2(13)$ & $9(33)$ \\
Salmeterol & $2(13)$ & $5(17)$ \\
Theophylline & $0(0)$ & $1(3.7)$ \\
Cromoglycate & $1(6.6)$ & $2(7.4)$ \\
Ipratropium & & \\
Asthma control, past 2 weeks & $0(0)$ & $6(22)$ \\
Missed school/decreased activity & $0(0)$ & $6(22)$ \\
Lower PEF than best & $0(0)$ & $14(51)$ \\
Wheeze & $0(0)$ & $13(48)$ \\
Night waking with asthma & $0(0)$ & $10(33)$ \\
Morning waking with asthma & $0(0)$ & $11(37)$ \\
Exacerbation of asthma &
\end{tabular}

Values are presented as mean \pm SEM or absolute number with percentage in parenthesis. Inhaled corticosteroid (IC) is expressed as mean daily dose per child. Three out of 15 children in the controlled group received bronchodilators daily, others used $\beta$ agonists less often, and prescribed only when needed. Twenty of the 27 children in the uncontrolled group received bronchodilators more than twice daily, others only when needed. +,++: $\mathrm{p}=$ $0.0007, \mathrm{p}=0.004$, using two sample t-test. FEV1: forced expiratory volume in one second; FEF25-75\%: forced mid-expiratory flow; BDR: bronchodilator response; OC: oral corticosteroid; PEF: peak expiratory flow. 
answers to these questions was classified as having symptomatic asthma. Symptomatic asthma together with a positive response to question 7, "have you had an exacerbation of asthma in the past 2 weeks?" was defined as having exacerbation of asthma.

Lung function. Each child performed three forced expiratory manoeuvres on a computerized spirometry system (Medgraphic, Pulmonary Function System 1070, Series 2, St. Paul, Minnesota, USA). Values were expressed as a percentage of the predicted value [9]. The best forced expiratory manoeuvre was used as the baseline value. Each child then inhaled $5 \mathrm{mg}$ of salbutamol delivered via Aerflo (Waite \& Co, Sydney, Australia) jet nebulizer and face mask. Ten minutes after nebulized salbutamol, spirometry was repeated and the best of three readings was taken as the postbronchodilator value. Bronchodilator response was expressed as the change in FEV1 as a percentage of the baseline value. Sputum induction was attempted if the FEV1 after bronchodilator response was at least $60 \%$ pred.

Sputum induction. Induced sputum samples were obtained by inhaling $4.5 \%$ hypertonic saline via an Omron NE-U06 ultrasonic nebulizer (Omron Corp, Tokyo, Japan) with an output of $3 \mathrm{~mL} \cdot \mathrm{min}^{-1}$, and mouthpiece. After measurement of the post bronchodilator FEV1, each child rinsed his/her mouth with water in order to remove the saliva. Hypertonic saline was inhaled for doubling time periods $(30 \mathrm{~s}, 1$, 2, $4 \mathrm{~min}$ ) and continued for a cumulative time of $20 \mathrm{~min}$ or until adequate sputum (i.e., at least three plugs) was obtained. FEV1 was measured for $1 \mathrm{~min}$ following each dose. Two puffs (100 $\mu \mathrm{g}$ each) of salbutamol (Ventolin; Allen \& Hanburys, Melbourne, Australia) from a pressurized metered dose inhaler via a Volumatic spacer (Allen \& Hanburys) were administered if the FEV1 dropped by $>10 \%$ from baseline. If salbutamol was administered, the child was observed until lung function improved.

Sputum analysis. Sputum was processed as described [5, $12]$ with modification. Briefly, the sputum volume was recorded, and the sample was poured into a petri dish and examined against a black background. The macroscopic characteristics were recorded and a $300 \mu \mathrm{L}$ aliquot of sputum plug was aspirated from the petri dish using a positive displacement pipette. The aliquot was added to $2,700 \mu \mathrm{L}$ of dithiothreitol 1.10 (Sputolysin; Calbiochem, La Jolla, CA, USA), mixed by rotating for $30 \mathrm{~min}$ at room temperature, and filtered through $50 \mu \mathrm{m}$ nylon gauze. A total cell count was performed using a Neubaur haemocytometer and cytocentrifuge slides prepared (Shandon Cytospin II, Sewickey, Pa, USA). Eosinophil counts were expressed as the mean percentage of 400 nucleated cells which were counted on each of two slides fixed with methanol and stained with Chromotrope 2R. Mast cells were identified in two further slides which were fixed with Carnoy's solution and stained with $0.5 \%$ toluidine blue in $0.7 \mathrm{~N}$ hydrochloric acid at $\mathrm{pH} 0.1 ; 1,500$ nucleated cells were counted on each of two slides and the mean of these two values reported as the mast cell count. A differential cell count was obtained from 200 cells counted on MGG stained slides. The quality of induced sputum samples was assessed based upon a slide quality assessment procedure which evaluated the presence of three parameters: 1) an adequate number of cells for enumeration; 2) the presence of pulmonary macrophages on the slide; and 3 ) the proportion of squamous epithelial cells. Cell number was scored as 0 if $<200$ cells, 1 if $200-399$ cells, and 2 if $>400$ cells were present. Pulmonary macrophages were scored as absent (1) or present (2). The proportions of squamous epithelial cells was scored 0 if $<50 \%$, and 1 if $>51 \%$. This gave a quality score ranging 0 (poor quality) to 6 (good quality sample).

\section{Ethics}

Written informed consent was obtained from parents and children. The study was approved by the Hunter Area Research Ethics Committee and the University of Newcastle Ethics Committee.

\section{Statistics}

Cell counts were expressed as the median and interquartile range (IQR). Mean values with $95 \%$ confidence intervals $(95 \% \mathrm{CI})$ were also reported in healthy subjects. There was a large proportion of zero counts and positive counts tended to be skewed. Eosinophils and mast cell counts were, therefore, categorized as the proportion of zero counts and nonzero counts for the purposes of comparison. Comparison of the demographic details between groups was performed using the Chi-squared test and Fisher's exact test. The Mann-Whitney test was used to compare continuous data which was distributed in a nonnormal fashion. The Kruskal-Wallis test was used to compare multiple groups $(n>2)$ and comparison between these groups was performed according to SPRENT [13]. A p-value $<0.05$ was considered statistically significance.

\section{Results}

\section{Normal controls}

The healthy nonasthmatic children included 29 males, and had a mean (SEM) age of 10.5(0.2) yrs. The mean (SEM) FEV1 was $97.6(1.1) \%$ pred and $32(44 \%)$ children were atopic. Cell counts from induced sputum and nasal smears are shown in table 2. Normal children had a median sputum total cell count of $1.5 \times 10^{6} \cdot \mathrm{mL}^{-1}$, with $0.3 \%$ of cells being eosinophils. The total cell count was significantly higher in the nonatopic group than the atopic group $(\mathrm{p}<$ 0.05 , Mann-Whitney test). The proportion of children with eosinophils observed in their sputum was higher in the atopic group than in the nonatopic normal group (45 versus $7.9 \%, \mathrm{p}<0.001$, Chi-squared test). There were no differences between the proportion of atopic children and nonatopic children with sputum mast cells (9.7 versus $7.9 \%$, ns), nasal eosinophils (34 versus $21 \%$, ns), and nasal mast cells (12.5 versus $7.7 \%$, Ns).

Asthma. The clinical characteristics of the children with asthma are shown in table 1 . The children were 12 (SEM: $0.4)$ yrs of age and 28 were male. There were 15 children with asthma controlled on inhaled corticosteroid and 27 with uncontrolled asthma, of whom 11 were experiencing an exacerbation. The children with uncontrolled asthma (symptomatic and exacerbation) had lower lung function, with six of the $27(22 \%)$ having an FEV $1<80 \%$ pred. The children with asthma controlled on inhaled corticosteroid reported no current asthma symptoms and all had an FEV1 
Table 2. - Cell counts in sputum and nasal smears from normal children

\begin{tabular}{lccc}
\hline & Normal & Atopic & Nonatopic \\
\hline TCC $\times 10^{6}$ cells·mL-1 & $\mathrm{n}=47$ & $\mathrm{n}=21$ & $\mathrm{n}=25$ \\
Mean $(95 \% \mathrm{CI})$ & $5.14(1.2,9.08)$ & $1.75(0.89,2.6)$ & $8.04(0.63,15.5)$ \\
Median (IQR) & $1.5(0.8,3.9)$ & $1.0(0.55,2.15)^{*}$ & $1.8(1.05,6)^{*}$ \\
Eosinophils \% sputum & $\mathrm{n}=70$ & $\mathrm{n}=31$ & $\mathrm{n}=38$ \\
Mean (95\% CI) & $1.57(0.62,2.52)$ & $2.16(0.83,3.48)$ & $1.13(0,2.54)$ \\
Median (IQR) & $0.3(0,1.05)$ & $0.5(0,2.8)$ & $0(0,0.6)$ \\
Mast cell \% sputum & $\mathrm{n}=70$ & $\mathrm{n}=31$ & $\mathrm{n}=38$ \\
Mean (95\% CI) & $0.024(0,0.05)$ & $0.03(0,0.07)$ & $0.02(0,0.06)$ \\
Median (IQR) & $0(0,0)$ & $0(0,0)$ & $0(0,0)$ \\
Eosinophils \% nasal & $\mathrm{n}=72$ & $\mathrm{n}=32$ & $\mathrm{n}=39$ \\
Mean (95\% CI) & $1.35(0.63,2.07)$ & $2.4(0.93,3.89)$ & $0.52(0,04,0.99)$ \\
Median (IQR) & $0(0,0.65)$ & $0(0,3.68)$ & $0(0,0.3)$ \\
Mast cell \% nasal & $\mathrm{n}=72$ & $\mathrm{n}=32$ & $\mathrm{n}=39$ \\
Mean (95\% CI) & $0.033(0,0.07)$ & $0.07(0,0.15)$ & $0.005(0,0.001)$ \\
Median (IQR) & $0(0,0)$ & $0(0,0)$ & $0(0,0)$ \\
\hline
\end{tabular}

TCC: total cell counts; IQR: interquartile range. 95\% CI: 95\% confidence interval. $t$ inadequate samples precluded assessment of sputum eosinophils and mast cells in two children. In one child, allergy skin tests were not performed. A total cell count was not obtained in 25 subjects because of technical difficulties. *: $\mathrm{p}<0.05$, using Mann-Whitney test.

$>80 \%$ pred. Both groups were using moderately high doses of inhaled corticosteroid therapy and were prescribed short-acting $\beta$-agonists.

Sputum eosinophils $(\mathrm{p}<0.0001$, Mann-Whitney test $)$ and epithelial cells $(\mathrm{p}<0.00005$, Mann-Whitney test) were significantly higher in children with asthma than with normal children (table 3). Each of the asthmatic groups had elevated sputum eosinophils ( $\mathrm{p}=0.0005$, Kruskal Wallis test), and epithelial cells ( $\mathrm{p}=0.0005$, Kruskal Wallis test), when compared with the normal control children. There was a nonsignificant trend to increased sputum eosinophils and epithelial cells in the children with an exacerbation of asthma (table 4). There were no significant differences in total cell counts between normal subjects, and children with asthma controlled on inhaled corticosteroid, sympto-

Table 3. - Comparison of sputum cell counts between normal subjects and children with asthma

\begin{tabular}{lcrl}
\hline & \multicolumn{1}{c}{$\begin{array}{c}\text { Normal } \\
(\mathrm{n}=72)\end{array}$} & $\begin{array}{c}\text { Asthma } \\
(\mathrm{n}=42)\end{array}$ \\
\hline $\mathrm{TCC} \times 10^{6}$ cells·mL $\mathrm{mL}^{-1}$ & $1.5(0.8,3.9)^{\dagger}$ & $2.2(1.07,4.65)$ \\
Eosinophils \% & $0.3(0,1.05)$ & $4.25(1.5,14.1)^{*}$ \\
Neutrophils \% & $35(12,88.25)$ & $43(26,57.3)$ \\
Macrophage \% & $56(10.5,77.25)$ & $37(17.5,46.8)$ \\
Lymphocyte \% & $0.5(0,1.5)$ & $0.5(0,1.5)$ \\
Epithelial cell \% & $1.5(0.75,3)$ & $14(6,19.4)^{*}$ \\
Number of subjects with & $6(8.6)$ & $4(9.5)$
\end{tabular}

sputum mast cells n (\%)

Values are presented as median and interquartile range in parenthesis. TCC: total cell count from cell suspension. Eosinophil from chromotrope $2 \mathrm{R}$ stained slides. Mast cells from toluidine blue stained slides. Remaining cell counts from MCG stained slides. *: $p<0.0005$, using Mann-Whitney test; ${ }^{\dagger}: \mathrm{n}=47$ for TCC. matic asthma or an exacerbation of asthma ( $p>0.05$, Kruskal Wallis test). Children with controlled asthma had higher eosinophils $(\mathrm{p}=0.012)$ and epithelial cells $(\mathrm{p}=0.015)$ than atopic asymptomatic children (tables 2 and 4). Sputum eosinophils were negatively correlated with FEV1 \% pred $(r=-0.41, p=0.006)$, whereas there was a weaker positive association between neutrophils and lung function $(\mathrm{r}=0.3, \mathrm{p}=0.03)$.

\section{Discussion}

This study reports values for induced sputum cell counts from healthy nonasthmatic children, and compares these to results from children with asthma that was controlled with inhaled corticosteroid, and to those with symptomatic asthma. The criteria for normality in this study were rigorous. All of the children had been followed from birth and had no history of wheeze, no diagnosed asthma, normal lung function and had normal airway responsiveness to hypertonic saline. Induced sputum from these normal children contained predominantly macrophages and neutrophils, reflecting the dominant cells in the airway lumen. By contrast, children with asthma had elevated numbers of eosinophils and desquamated bronchial epithelial cells. These features of asthmatic airway inflammation persisted in children whose asthma was controlled on high-dose inhaled corticosteroid therapy, albeit at a lower level than in children with symptomatic asthma.

The finding of elevated sputum eosinophils in asthmatic patients extends the published data from adults [14] to childhood asthma. The eosinophil is believed to be one of the main effector cells in asthma and accumulates within

Table 4. - Comparison of sputum cell counts in normal subjects (NC), controlled asthma (CA) on inhaled corticosteroid, symptomatic asthma (SA) and those with exacerbation of asthma (EA)

\begin{tabular}{|c|c|c|c|c|}
\hline & $\begin{array}{c}\mathrm{NC} \\
(\mathrm{n}=72)\end{array}$ & $\begin{array}{c}\text { CA } \\
(n=15)\end{array}$ & $\begin{array}{c}\text { SA } \\
(n=16)\end{array}$ & $\begin{array}{c}\text { EA } \\
(n=11)\end{array}$ \\
\hline$\overline{\mathrm{TCC}}$ & $1.5(0.8,3.9)$ & $1.9(1.0,7.5)$ & $1.7(0.9,4.1)$ & $2.5(1.6,5.4)$ \\
\hline Eosinophi & $0.3(0,1.05)^{+}$ & $2.5(1.5,0.75)$ & $3.8(2.4,15.1)$ & $8.5(1.5,20.0)$ \\
\hline Neutrophils \% & $35(12.0,88.0)$ & $46.5(29.5,58.5)$ & $47.0(24.8,57.8)$ & $27.0(22.5,42.0)$ \\
\hline Epithelial cell \% & $1.5(0.8,3.0)$ & $10.5(5.0,17.5)$ & $11.5(5.5,21.3)$ & $18.0(6.0,28.0)$ \\
\hline $\begin{array}{l}\text { Subjects with mast } \\
\text { cells } n(\%)\end{array}$ & $6.0(8.3)$ & $0.0(0.0)$ & $1.0(6.20)$ & $3.0(27.0)$ \\
\hline
\end{tabular}

Values are presented as median and interquartile range, or as absolute number and percentage. ${ }^{+}: \mathrm{p}=0.0005$, using Kruskal Wallis test. $n=47$ for total cell count (TCC) from normal subjects. 
the airway lumen in response to cytokines such as interleukin (IL)-5 produced by type 2 T-helper cell (Th2)-lymphocytes and releases granule-associated proteins to cause airway mucosal damage, including epithelial detachment. The increase in airway eosinophils is one of the most characteristic findings in asthma.

We also found that significant epithelial shedding occurred together with eosinophilic airway inflammation. The median epithelial cell count in sputum from asthmatic children was several fold higher (14\%) than from normal subjects (1.5\%). Although this has been well-documented in adults with asthma $[15,16]$, and some epithelial damage has been reported in children with chronic cough [17], the marked epithelial shedding reported in this study is a novel finding in childhood asthma. This study clearly demonstrates the degree of epithelial damage which can occur in children with asthma, even when this is controlled. Hypertonic saline inhalation is unlikely to be contributory since both groups (normal and asthma) inhaled hypertonic saline and prior work has found no effect of hypertonic saline on epithelial loss in asthma [18]. Both groups of children had sputum induced after inhalation of hypertonic saline. This is a reliable technique which is not known to alter sputum eosinophil or epithelial cell counts [18-20] and the results from different ultrasonic nebulizers are comparable $[18,20]$. The asthmatic children inhaled $\beta_{2}$-agonist prior to sputum induction. This was done for safety purposes, in order to prevent airway obstruction [5]. It does not alter sputum cellularity [20].

The airway epithelium is now seen as playing a pivotal role in the inflammatory response in asthma [21]. When activated, epithelial cells can be a source of eosinophilattracting cytokines such as regulated on activation, normal T-cell expressed and secreted factors (RANTES) [22], and eotaxin [23]. Epithelial loss may contribute to the genesis of airway hyperresponsiveness, and to microvascular leakage [24] in asthma. The data from this study identify that epithelial loss is an integral part of asthma in children, and that it occurs in association with eosinophilic inflammation.

This study also examined the relationship between asthma control and airway inflammation. The children with controlled asthma had minimal symptoms and normal lung function. By contrast, those children with uncontrolled asthma reported symptoms, increased use of bronchodilators and reduced lung function. We found that both sputum eosinophils and epithelial cells were at significantly higher levels in uncontrolled asthma compared with levels in normal children. Interestingly, we found that the numbers of eosinophils and epithelial cells in sputum were also higher in controlled asthma than in normal children, including atopic asymptomatic children. This suggests that eosinophilic inflammation occurs even when the clinical features of asthma are suppressed by high-dose inhaled corticosteroid therapy. Corticosteroid therapy reduces airway inflammation [2] and epithelial damage [3] when measured using bronchial biopsy $[2,3]$, and sputum [25]. Although some studies in adults suggest that airway eosinophilia is abolished by corticosteroid therapy [25], this is not a uniform finding [2,3]. Our results indicate that in children, just as in adults [2], there may be a component of asthmatic airway inflammation that is relatively resistant to corticosteroid therapy. It will be important to establish this using prospective studies of treatment in children with asthma.

We found that relatively few children had mast cells in their sputum. Mast cells were found in only four of the 42 asthmatic children. This contrasts with adult asthma where mast cells are frequently seen $[5,26]$. Possible explanations are that the mast cells were present in the airway but degranulated, or restricted to the airway wall only. GIBSON $e t$ al. [27] demonstrated increased mast cells in the bronchial epithelium of adults with asthma, but not in bronchoalveolar lavage (BAL) fluid. Other studies support the epithelial accumulation of mast cells in asthma [28], and find no difference in lamina propria mast cells [29]. A third possibility is that corticosteroid therapy may eradicate mast cells from the airway in asthma. The literature, however, reports a reduction but not a complete clearance of mast cells from the airway with corticosteroid therapy $[2,25]$. At the present time the significance of airway mast cells in childhood asthma requires further study.

This study also provides interesting comparative data on sputum cell counts in atopic and nonatopic children without asthma. In the nonatopic normal group, the sputum total cell count was higher than in the atopic normal group. This was an unexpected finding and remains unexplained. We found that atopic normal children were more likely to have sputum eosinophils than nonatopic normal children. Eosinophils were observed in the sputum of $45 \%$ of the atopic children compared with $7.9 \%$ of the nonatopic children. This is consistent with the finding by DuKANOVIC et al. [30], who found higher numbers of airway eosinophils in bronchial biopsies from atopic non-asthmatic adults than a nonatopic normals. These data indicate that the atopic state can be associated with mild airway inflammation without any evidence of airway hy-perreactivity or clinical asthma. This finding may be of relevance to both the mechanisms of symptom generation in asthma, and to the future development of asthma. Since atopic nonasthmatics have a mild degree of airway eosinophilia but no asthma symptoms, this suggests that there may be a threshold in the intensity of airway inflammation that is required before symptoms become apparent. Alternative possibilities are that either additional cell types are required (e.g. mast cells), or additional features such as airway hyperreactivity are necessary for symptoms to develop. Allergic rhinitis and atopy are both risk factors for the subsequent development of asthma. The finding of mild airway inflammation in some atopic nonasthmatic children raises the possibility that this may predispose them to future symptomatic asthma, an hypothesis which could be tested in a prospective study.

In our study, we did not find a significant difference in nasal eosinophils and mast cells between atopic and nonatopic groups. IGARASH et al. [31] reported that nasal biopsies from allergic subjects contained significantly more eosinophils than did biopsies from normal subjects. However, the difference in the number of mast cells between the two groups did not reach significance. The difference in nasal eosinophils between their study and ours may relate to subject characteristics. All of their allergic subjects had a history of seasonal rhinitis, while in our study, only eight of the 32 atopic normal subjects reported a history of rhinitis. In support of this, we found a nonsignificant trend for increased nasal eosinophils in the children with allergic rhinitis (data not shown). 
In conclusion, sputum induction using hypertonic saline provides opportunities for increasing our understanding of airway inflammation in asthma. Sputum from children without asthma contains airway neutrophils and macrophages. Airway inflammation was found in children with asthma, even when this was well controlled. The dominant inflammatory cells were epithelial cells and eosinophils. However, unlike in adult asthma, mast cells were seldom seen. Further work is required to determine whether airway inflammation is a marker of asthma, controlled or un-controlled, and whether deteriorating asthma control is associated with an increase in airway inflammation.

Acknowledgements: The authors would like to thank A. Wilson and R. Hankin for their help in data collection and to L. Francis for assistance with data analysis. The study was funded by the NH\&MRC, Australia. The RIFYL team, consisting of R. Clancy, M.J. Hensley, A. Cripps, M. Gleeson, J. Wlodarczyk contributed to the initiation and ongoing study of the birth cohort.

\section{References}

1. Busse W, Banks-Schlegel SP, Larsen GL. Childhoodversus adult- onset asthma. NHLBI-NIH Workshop Summary. Am J Respir Crit Care Med 1995; 151: 1635-1639.

2. Booth H, Richmond I, Ward C, Gardiner PV, Harkawat R, Walters EH. Effect of high dose inhaled fluticasone propionate on airway inflammation in asthma. Am J Respir Crit Care Med 1995; 152: 45-52.

3. Laitinen LA, Laitinen A, Haahtela T. A comparative study of the effects of an inhaled corticosteroid, budesonide, and a beta2-agonist, terbutaline, on airway inflammation in newly diagnosed asthma: a randomized, double-blind, parallel-group controlled trial. J Allergy Clin Immunol 1992; 90(1): 32-42.

4. Kirby JG, Hargreave FE, Gleich GJ, O'Byrne PM. Bronchoalveolar cell profiles of asthmatic and non-asthmatic subjects. Am Rev Respir Dis 1987; 136: 379-383.

5. Pin I, Gibson PG, Kolendowicz R, et al. Use of induced sputum cell counts to investigate airway inflammation in asthma. Thorax 1992; 27: 25-29.

6. Gleeson M, Cripps AW, Clancy RL, Husband AJ, Hensley MJ, Leeder SR. Ontogeny of the secretory immune system in man. Med J Aust 1982; 12: 255-258.

7. Gleeson M, Clancy RL, Hensley MJ, et al. Development of bronchial hyperreactivity following transient absence of salivary IgA. Am J Respir Crit Care Med 1996; 153: $1785-1789$.

8. Riedler J, Reade T, Dalton M, Holst DI, Robertson CF. Hypertonic saline challenge in an epidemiological survey of asthma in children. Am J Respir Crit Care Med 1994; 150: $1632-1639$.

9. Knudson RJ, Slatin RC, Lebowitz MD, Burrows B. The maximum expiratory flow volume curve: normal standards, variability, and effects of age. Am Rev Respir Dis 1976; 113 587-600.

10. Lee HS, Majima Y, Sakakura Y, Shinogi J, Kawaguehi S, Kim BW. Quantitative cytology of nasal secretions under various conditions. Laryngoscope 1993; 103: 533-537.

11. Gibson PG, Stuart JE, Wlodarczyk J, Olson LG, Hensley MJ. Nasal inflammation and chronic ear disease in Australian Aboriginal children. J Padiatr Child Health 1996; 32: $143-147$

12. Popov T, Gottschalk R, Kolendowicz R, Dolovich J, Poweres $\mathrm{P}$, Hargreave FE. The evaluation of a cell dispersion method of sputum examination. Clin Exp Allergy 1994; 24: 778-783.

13. Sprent P. Applied Nonparametric Statistical Methods. London, Chapman and Hall, 1989; pp. 113-122.

14. Fahy JV, Liu J, Wong H, Boushey HA. Cellular and biochemical analysis of induced sputum from asthmatic and from healthy subjects. Am Rev Respir Dis 1993; 147: 1126-1131.

15. Montefort S, Roberts JA, Beasley R, Holgate ST, Roche WR. The site of disruption of the bronchial epithelium in asthmatic and non-asthmatic subjects. Thorax 1992; 47: 499-503.

16. Oddera S, Silvestri M, Balbo A, et al. Airway eosinophilic inflammation, epithelial damage, and bronchial hyperresponsiveness in patients with mild-moderate, stable asthma. Allergy 1996; 51: 100-107.

17. Heino M, Juntunen-Backman K, Leijala M, Rapola J, Laitinen LA. Bronchial epithelial inflammation in children with chronic cough after early lower respiratory tract illness. Am Rev Respir Dis 1990; 141: 428-432.

18. Pizzichini MMM, Popov TA, Pizzichini E, et al. Spontaneous and induced sputum compared. Am J Respir Crit Care Med 1996; 154: 866-869.

19. Makker HK, Walls AF, Goulding D, et al. Airway effects of local challenge with hypertonic saline in exerciseinduced asthma. Am J Respir Crit Care Med 1994; 149: 1012-1019.

20. Popov TA, Pizzichini MMM, Pizzichini E, et al. Some technical factors influencing the induction of sputum for cell analysis. Eur Respir J 1995; 8: 559-565.

21. Levine SJ. Bronchial epithelial cell-cytokine interactions in airway inflammation. J Investig Med 1995; 43: 241249.

22. Wang JH, Devalia JL, Xia C, Sapsford RJ, Davies RJ. Expression of RANTES by human bronchial epithelial cells in vitro and in vivo and the effect of corticosteroids. Am J Respir Crit Care Med 1996; 14: 27-35.

23. Garcia-Zepeda EA, Rothenberg ME, Owebey RT, Celestin J, Leder P, Luster AD. Human eotaxin is a specific chemoattractant for eosinophil cells and provides a new mechanism to explain tissue eosinophilia. Nat Med 1996; 2: 449-456.

24. Erjefalt JS, Sundler F, Persson CG. Eosinophils, neutrophils and venular gaps in the airway mucosa at epithelial removal-restitution. Am J Respir Crit Care Med 1996; 153: $1666-1674$.

25. Gibson PG, Hargreave FE, Girgis-Gabardo A, Morris M, Denbury JA, Dolovich J. Chronic cough - eosinophilic bronchitis: response to corticosteroid and examination for variable airway obstruction. Clin Exp Allergy 1995; 25: 127-132.

26. Gibson PG, Girgis-Gabardo A, Morris MM, Denberg JA, Dolovich J, Hargreave FE. Cellular characteristics of sputum from patients with asthma and chronic bronchitis. Thorax 1989; 44: 693-699.

27. Gibson PG, Allen CJ, Yang JP, et al. Intraepithelial mast cells in allergic and nonallergic asthma. Assessment using bronchial brushings. Am Res Respir Dis 1993; 148: 80-86.

28. Pesci A, Foresi A, Bertorelli G, Chetta A, Oliveri D. Histochemical characteristics and degranulation of mast cells in epithelium and lamina propria of bronchial biopsies from asthmatic and normal subjects. Am Res Respir Dis 1993; 147: 684-689.

29. Djukanovic R, Wilson JW, Britten KM, et al. Quantitation of mast cells and eosinophils in the bronchial mucosa of symptomatic atopic asthmatic and healthy control subjects using immunohistochemistry. Am Rev Respir Dis 1990; 142: 863-871.

30. Djukanovic R, Lai CKW, Wilson JW, et al. Bronchial mucosal manifestations of atopy: a comparison of markers of inflammation between atopic asthmatics, atopic nonasthmatics and healthy controls. Eur Respir J 1992; 5: $538-544$.

31. Igarashi Y, Goldrich MS, Kaliner MA, Irani AM A, Schwartz LB, White MV. Allergens, IgE, mediators, inflammatory mechanisms. Quantitation of inflammatory cells in the nasal mucosa of patients with allergic rhinitis and normal subjects. J Allergy Clin Immunol 1995; 95: $716-725$. 